\title{
The Design of Innovative Leadership Systems Inside University Using Disneyland Concepts to Face Globalization
}

\author{
Indra Gamayanto ${ }^{1}$, Arta Moro Sundjaja ${ }^{2}$ \& Titien S. Sukamto ${ }^{1}$ \\ ${ }^{1}$ Department Of Information Systems, Dian Nuswantoro University, Semarang, Indonesia \\ ${ }^{2}$ Department Of Information Systems, Bina Nusantara University, Jakarta, Indonesia \\ Correspondence: Indra Gamayanto, Faculty of computer science, Department of Information Systems, Dian \\ Nuswantoro University (UDINUS), Semarang, Imam Bonjol Street No.207, Semarang, Tel: 24-351-7261, Fax: \\ 24-356-9684. E-mail: indra.gamayanto@dsn.dinus.ac.id
}

Received: May 8, 2018; Accepted: May 30, 2018; Published: June 12, 2018

The research is financed by ATEK FOODS - Suplliers.

\begin{abstract}
The University is one of the most important pillars of a State. Therefore, the university should be able to produce high-quality human resources and can contribute greatly to the progress of a country in various sectors. Highquality human resources will be able to change the culture of a region, a city and even a country toward a better future, not only in certain sectors but almost all sectors. The main problem in the university, the lecturer is not placed in the right position and still lack of experience possessed by the lecturer, in terms of experience with the subjects taught. This will be answered by using the concept held by Disneyland and this concept developed into a formula $L=D^{3}$. B. The formula, we created will help in the development of human resources at the university level, with the focus being lecturers and students. furthermore, this formula will greatly assist the university to be able to accept lecturers who have the competence and guide the students to achieve the maximum in themselves, all these things will be able to improve the living standard of the people's economy, with high-quality human resources, it will be able to there is a significant change in the life process, in the future
\end{abstract}

Keywords: Disneyland, University, Lecturer-Students, Human resource systems, Innovations

\section{Introduction}

Management means to make human beings fully human, have a purpose in life, able to cooperate effectively and efficiently, and able to grow in character. In the context of human resources, human beings are the main assets that should not only be regarded as a means to gain profit but as partners in mutual benefit. At the university level, lecturers are a leader for the future of students and themselves, and this will be applied using the Disneyland method, which can provide an innovation in human resource development. Here there are challenges to the question that many people ask when the survey is conducted, the question in the data collection is: "If a person has become successful with whatever he/she does, without completing his / her studies at the university, should the person be given a graduation certificate or not?", this is a paradox question that on the one hand, the person is actually worthy of an academic degree, if this is seen from the side of the ability and the evidence he/she has done, on the other hand, the system at the university does not allow to be done, because it must follow the process inside university, as a society to get an academic degree. Therefore, it takes a method that can overcome this and can provide a solution. How to get data in this journal is by interviewing students and lecturers, in three universities with 100 participants as the initial data for this journal, and growing to 150 people.

If participants answer 10-30: no need to change; 40: there needs to be a slight change in a few things; 50: hesitate; 60-80: innovation needs to be done in several ways; 90-100: needs to be innovated as a whole and/or $80 \%$. From the surveys and interviews conducted, resulting in:

100 participants are in range: 60-100 points- participants said that changes need to be made in order to improve the education in Indonesia, especially the lecturers 'resources that need to be developed and the students' resources into the university. 
40 participants are in the range: 10-40 Points- participants said that the university only needs to do a little improvement and do not need to develop innovation. In this position, the participants are looking for a safe and comfortable with what they get now.

10 participants are in the range: 50 Points- participants will not answer and/or hesitate. Participants from 3 questions choose the number 50 .

Table 1. Interview \& Survey - Questions

\section{Questions}

Lecturers at universities need to develop themselves from the experience side and not just focus on the theory- Whether this is necessary or not required or $50 \%$ is required?

Is it necessary to apply new teaching methods in the course in order to contribute to the future?

From points 10 to 100 , how many points does the university need to change the method of receiving lecturer's resources and innovation in the learning process?

\section{Points}

102030405060

708090100

102030405060

708090100

102030405060

708090100

There are data that UNESCO has on the education system in Indonesia, and this data is used as an innovation development in this journal:

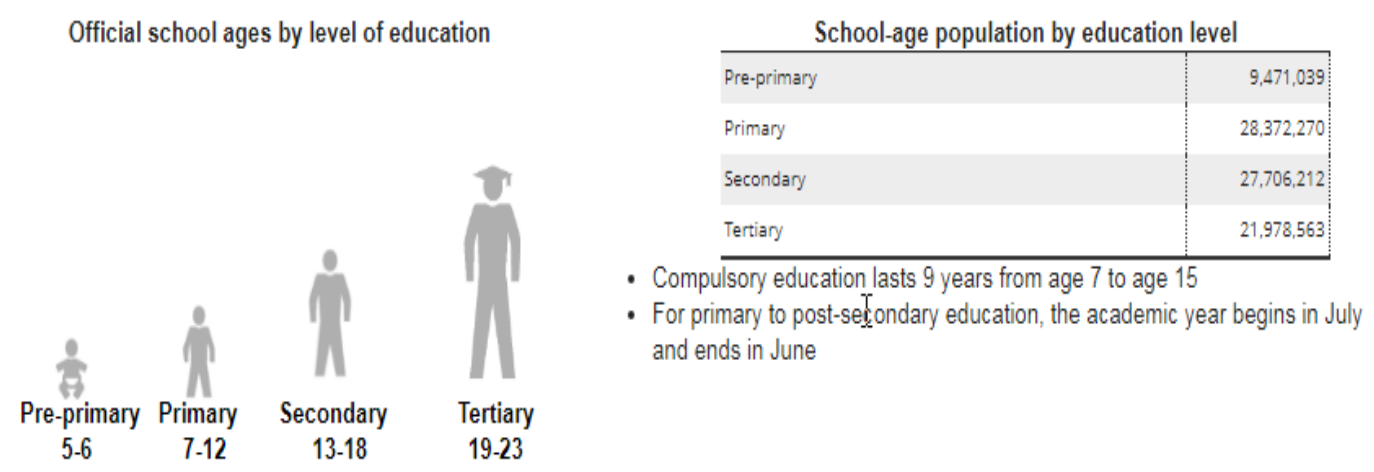

Figure 1. Education Systems in Indonesia (UNESCO Indonesia)

This data continues to grow and produce other data, which provides detailed information about the literacy rate in Indonesia:

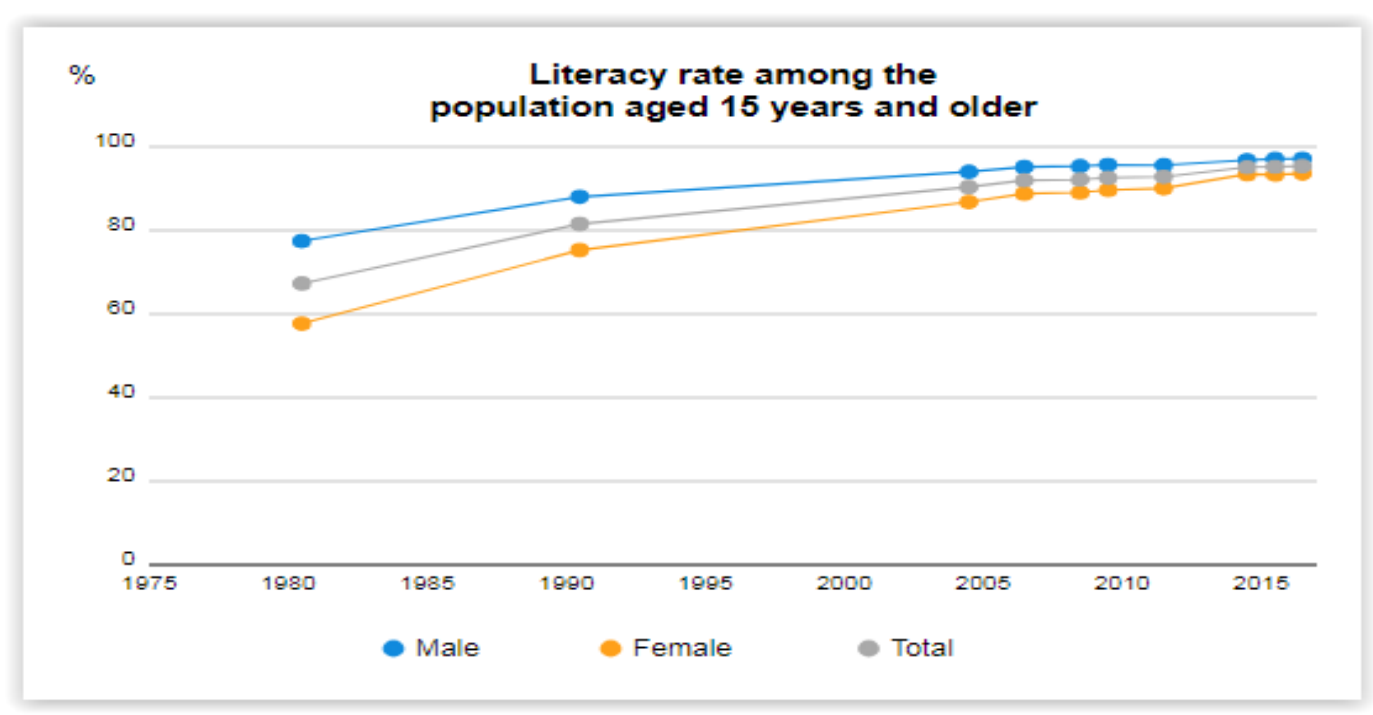

Figure 2. Literacy Rate -15 years and older (UNESCO Indonesia) 


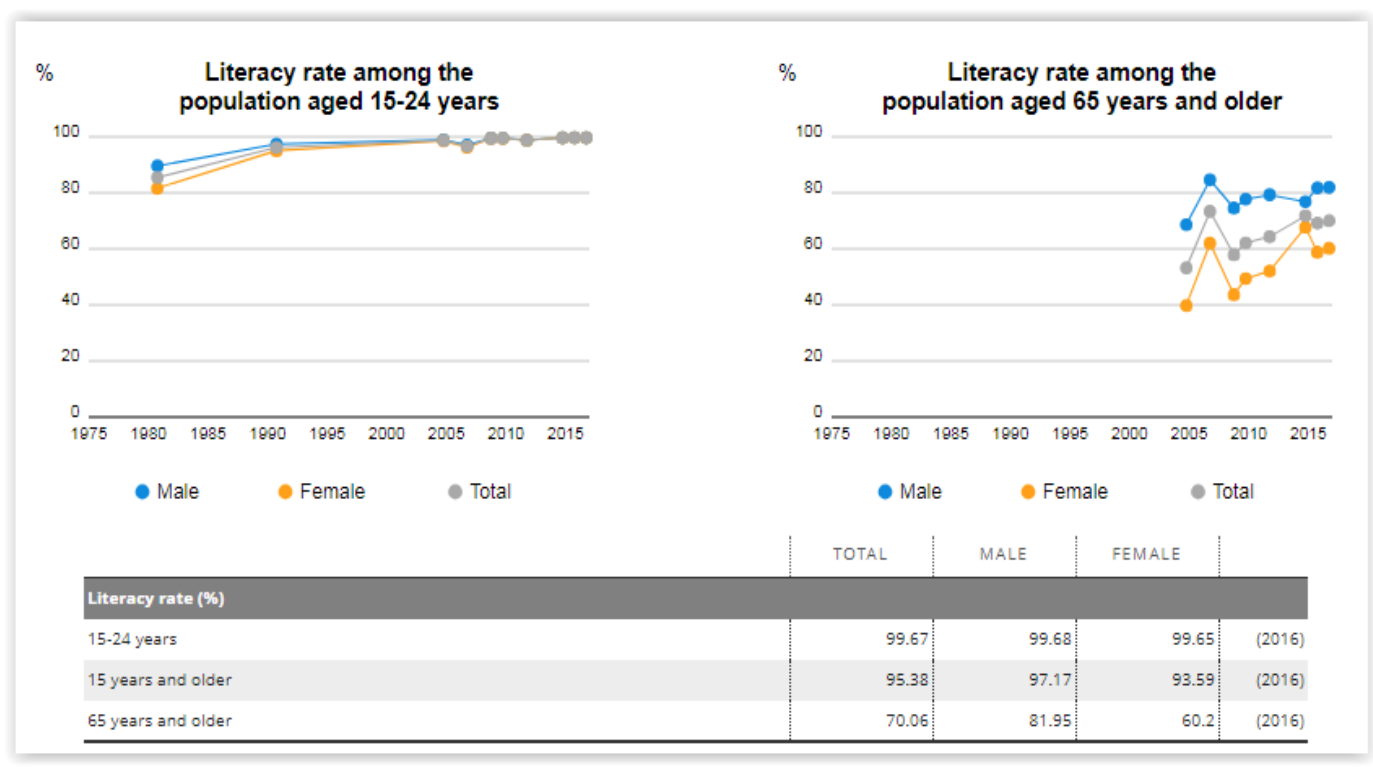

Figure 3. Literacy Rate- 15-24 years old \& 65 years old and older (UNESCO Indonesia)

From the explanation above, it can be seen still needed innovation in the world of education and these need to be done in facing globalization so that it can give impact to economic growth and give impact to society prosperity in life by improving education quality.

In this journal, the main contexts and content of the study are universities, we all know that universities are central to producing reliable human resources; therefore, a method that is capable of changing an input, process, and output is required. The main problem is that there are still many lecturers who have not worked in accordance with the right position; the absence of a place to develop knowledge and culture that is formed is not conducive. For Instance, environments, conditions, and situations will make the work environment uncomfortable and cannot be controlled properly, it will be able to produce human resources that only work in accordance with what it obtains in accordance with company standards, but are unable and/or unwilling to provide maximum results to the company where he works. This journal is the development of two journals: (1) Jonathan Matusitz, Disney's successful adaptation in Hong Kong: A glocalization perspective, Asia Pacific Journal Management, and (2) RN Pratikna, I Gamayanto, Developing Leadership Systems Inside University Using Jim Collins Method [ Good to Great]: People Management Development to Face ASEAN Economic Community in Indonesia(Pratikna \& Gamayanto, 2017). From these two journals, we know that globalization and the development of reliable human resources are needed so that these developments can benefit humans. The method used is the 7S Mckinsey and Dreamland concept Dream, where both of these concepts will be able to produce a formula of human resources and/or reliable lecturer resource formula, side effects from reliable lecturer's resources will be generated also students who have quality high, so that Indonesia will be able to face globalization.

\section{Method}

According to figure 4, the first process is to analyze Disneyland and some literature as the main support in this journal, the second process - using the 7S's McKinsey method, which will be used to analyze Disneyland briefly, but our focus is not on the application of this method, McKinsey's 7S's method will help us in analyzing what should be within the university, especially in human resource development. The next process is to explain Disneyland's concepts (Dream-Believe-Dare-Do), which are the basic concepts that will then be developed to the development of the formula $\mathrm{L}=\mathrm{D}^{3}$. $\mathrm{B}$, this is a formula we created to develop human resources at the university level, and this formula can be applied at all universities, not just in Indonesia. This formula will be able to help the university to get high-quality lecturer and student resources and can improve the quality of human resources. 


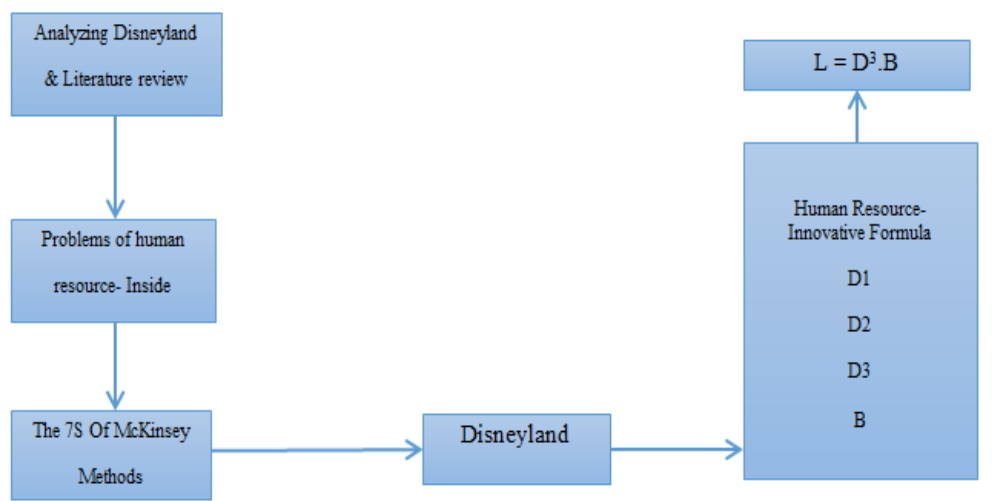

Figure 4. The Process of D1-D2-D3-B- Human Resource - Innovative Formula L = D ${ }^{3} . \mathrm{B}$

\section{Results \& Discussion}

\section{A. Disneyland Concepts}

The concept of Disneyland is a very flexible concept and can be applied in various sectors, one of which is the University. Dream-Believe-Dare-Do concept, making Disneyland, one of the largest companies in the world:

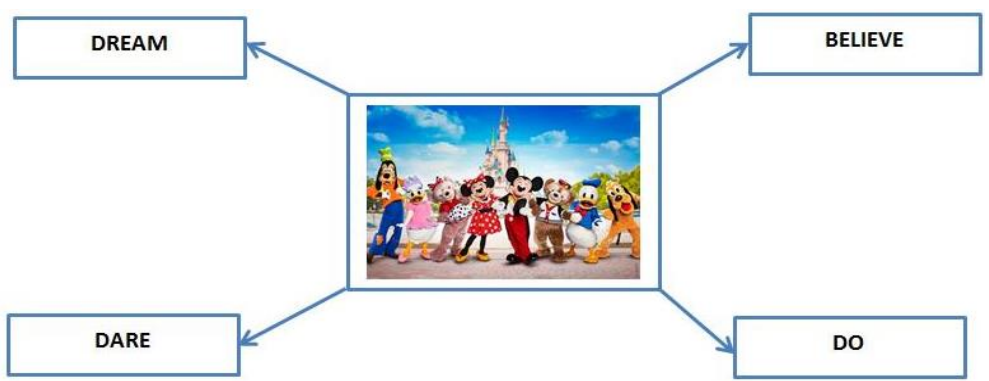

Figure 5. Disneyland Concepts-Dream-Believe-Dare-Do

This concept is a foundation for building strength within the company, and in those four things, there are 10 beliefs that are the foundation of Disneyland: (1) Give every member of our organization the opportunity to dream and seek creativity. contained in the dream; (2) Sticking to our beliefs and principles; (3) Treat our customers as guests; (4) Support, empower, and award employees; (5) Establish long-term relationships with our suppliers and employment spell enterprises; (6) Dare to take calculated risks to run innovative ideas to fruition; (7) Extensive training and consistently instill corporate culture; (8) align long-term vision with short-term implementation; (9) Use storyboarding techniques to solve planning and communication problems; (10) Pay close attention to the little things.

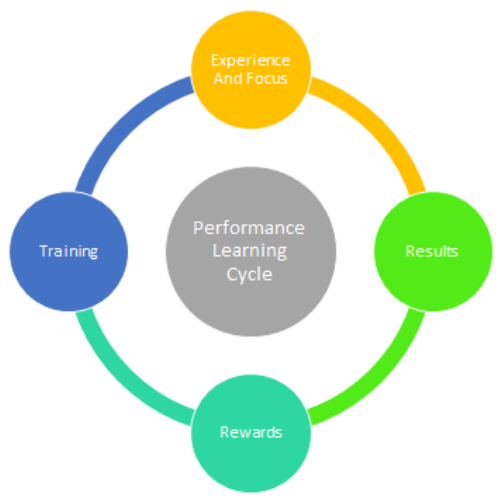

Figure 6. Performance Learning Cycle- Disneyland 
According to figure 6, the Performance learning cycle illustrated, is a very important depth of training, so all companies have to ask themselves, "Are we enough to give our employees the right kind of training?", This means equipping employees with techniques which they need to achieve customer-focused outcomes and then followed by a ready-to-assist situation that offers an opportunity to train ideas and learn from what experiences work and what cannot be done, all under the supervision of a trainer who has been experienced. The next step is a measurement of achievement and recognition at the right time. Needless to say, that the recognition and rewards of employee contribution are essential to improving the desired behavior. Without the expression of appreciation, enthusiasm, and hard work necessary for further development, it can be lost. A person who earns praise for having accomplished something will usually respond with a better outcome. In the end, the company can expect the results obtained by these employees to be translated in the form of cost savings, quality improvement, reduced cycle time, and strengthening the relationship with consumers. The rewards have different meanings for different people, so how an organization chooses to recognize achievements depends on the existing situation and the culture of the organization. Disneyland uses various kinds of celebrations, awards, letters of appreciation for outstanding service, and other kinds of internal rewards. A series of words of appreciation from a respected leader can result in many, or small rewards to the team can help build employee morale, perhaps dinner at an informal restaurant or party in the office. Of course, giving a bonus in the form of money is always a worthwhile thing, but when awards in money are not possible, look for other forms of reward. When the newly learned skills are strengthened with the help of trainers, exercises, and rewards, it will produce human resources that have high quality. Such expertise will become a habit and these habits will move the company by moving towards a step up.

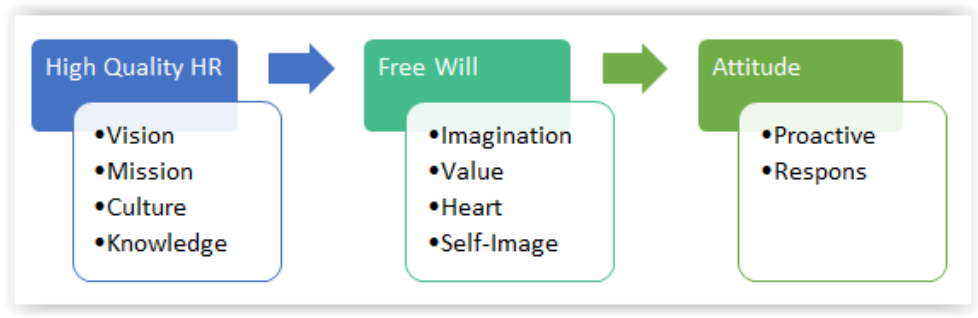

Figure 7. Attitude Process

The goal of learning is to develop positive habits that benefit individuals and organizations. When learning a foreign language, such as Spanish, the first thing students learn is that they can be understood and understood in a social setting. This is a useful but very limited skill. If the person is living in a Spaniard country, his limited skills will initially not suffice the need to do things. The language must become a habit, an unintentional reaction before students are fully comfortable with the language, but it will not happen until the person is trained, and then trained again. Aristotle says, "We are what we do repeatedly ... therefore, excellence is not an act but a habit". If so, an organization that wants to have superior performance at all levels must ensure that the characteristics that define excellence are practiced, and then trained continuously, until the characters also become unintentional reactions. We must believe that good habits grow from acquiring knowledge, attitude, and skill. Knowledge is an understanding of what, how and why we need to do something. Skill is applying that knowledge to a practical situation. Attitude is a desire to turn knowledge into skills and eventually become a habit.

\section{B. 7S's Mckinsey Concepts-Disneyland}

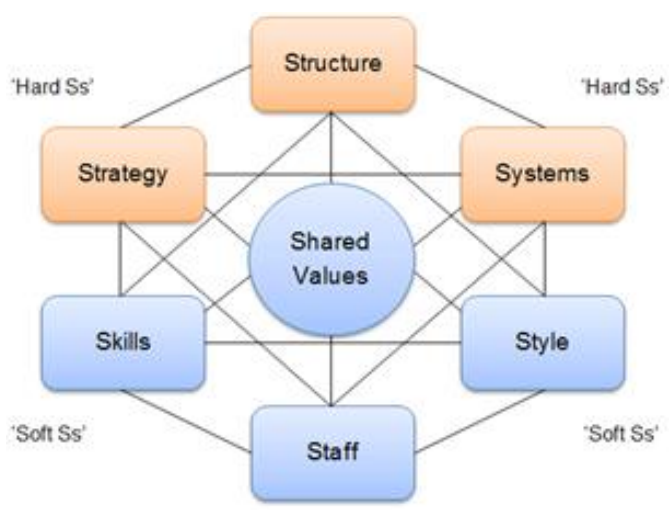

Figure 8. The 7S's McKinsey Methods 
According to figure 8, Shared Values: the core values of a company that has become a culture; Strategy: A plan designed to maintain and build competitive advantage in competition; Structure: the way the organization systematically regulates who reports to whom; Systems: a procedure for organizing a running activity that involves an organization member to complete a job; Style: The leadership style used; Staff: The organization will determine the prerequisites of what kind of people are deemed appropriate to the existence and purpose of the organization; Skills: Skills the organization needs. The analysis results using the 7S's McKinsey are as follows: (1) Shared Value-"The mission of The Walt Disney Company is to be one of the world's leading producers and providers of entertainment and information. Using our portfolio of brands to differentiate our content, services, and consumer products, we seek to develop the most creative, innovative and profitable entertainment experiences and related products in the world". (2) Structure- Management Team (A commitment to excellence, creativity, and innovation. Our executive team's vision and strategic direction deliver stories, characters, and experiences that are welcomed into the hearts and homes of millions of families around the world) \& Board of Directors (The Walt Disney Company's Board of Director's hail from renowned global organizations and industries, bringing a diverse range of knowledge, perspective, and experience to guide and drive long-term value to the company); (3) Strategy- The Walt Disney Company, together with its subsidiaries and affiliates, is a leading diversified international family entertainment and media enterprise with the following business segments: media networks, parks, experiences and consumer products, studio entertainment, direct-to-consumer and international.; (4) Systems- Ethical sourcing of Disney-branded products is an important focus of our overall corporate citizenship efforts. We promote the ethical production of Disney-branded products by working to improve labor conditions in production facilities, testing the safety and integrity of products, and exploring ways to reduce the environmental footprint of our supply chain.; (5) Style- Disney's stories, characters, and experiences reach consumers and guests from every corner of the globe. With operations in more than 40 countries and territories, our employees and cast members work together to create entertainment experiences that are both universally and locally cherished; (6) Staff \& (7) Skills: Disney's International Labor Standards (ILS) Program evaluates and helps improve working conditions in facilities producing Disney-branded products. Disney's ILS Program is administered by a dedicated staff of over 120 professionals located in 12 countries around the world. The breadth and diversity of our consumer products business mean that Disney-branded products are produced in over 34,000 facilities in more than 100 countries. As a result, we face unique challenges in achieving and monitoring performance against our high expectations and requirements. The Disney ILS Program has developed many innovative approaches to manage this extended supply chain, and by working with our licensees and vendors as well as our many interested stakeholders, we continue to help foster safe, inclusive and respectful workplaces wherever Disney-branded products are produced. This is the result of our brief analysis; our focus on this journal is how to apply the Disneyland concept to the University, especially in Indonesia.

\section{Disneyland Concepts $-\mathbf{L}=D^{3}$.B- Implementation Inside University}

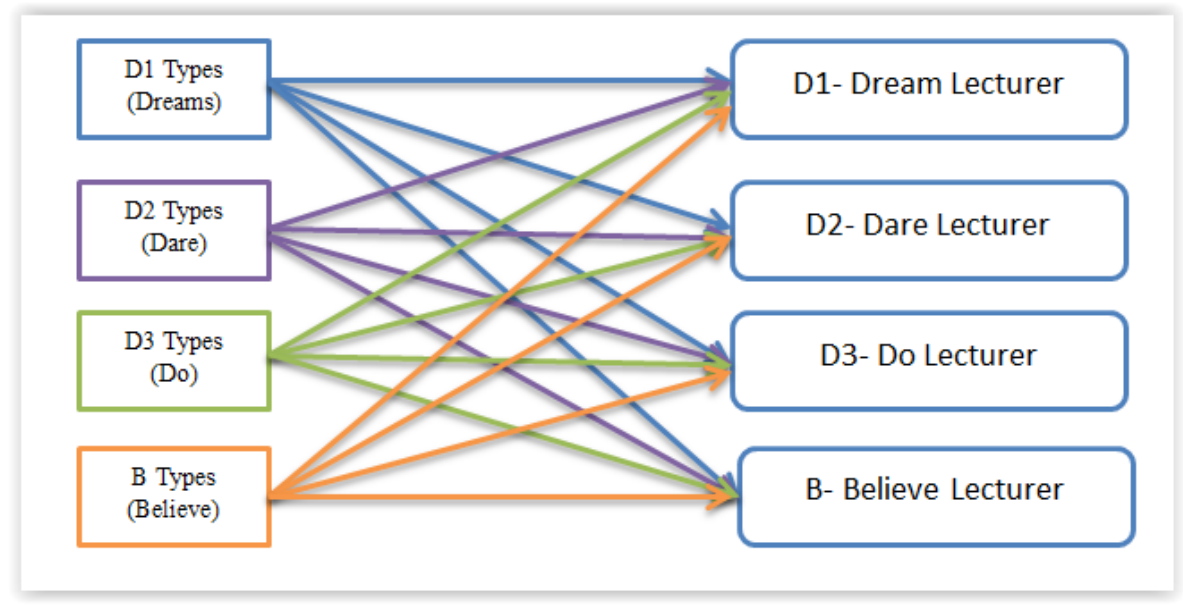

Figure 9. Innovation of Disneyland Concepts- Implementation Inside University

According to figure 6, we can see that there is a framework to map in detail various types of lecturer so that the lecture process can be more effective and efficient, in advance this innovation will be able to help the university to have the right and accurate lecturers resources. 
Table 1. Types of Lecturer- In Details

\begin{tabular}{llll}
\hline $\mathbf{D} 1+\mathbf{D} 1$ & $\mathbf{D} 2+\mathbf{D} 1$ & $\mathbf{D 3}+\mathbf{D} 1$ & $\mathbf{B}+\mathbf{D} 1$ \\
$\mathbf{D} 1+\mathbf{D} 2$ & $\mathbf{D} 2+\mathbf{D} 2$ & $\mathbf{D 3}+\mathbf{D 2}$ & $\mathbf{B}+\mathbf{D} 2$ \\
$\mathbf{D} 1+\mathbf{D 3}$ & $\mathbf{D} 2+\mathbf{D 3}$ & $\mathbf{D 3}+\mathbf{D 3}$ & $\mathbf{B}+\mathbf{D 3}$ \\
$\mathbf{D} 1+\mathbf{B}$ & $\mathbf{D} 2+\mathbf{B}$ & $\mathbf{D 3}+\mathbf{B}$ & $\mathbf{B}+\mathbf{B}$ \\
\hline
\end{tabular}

According to table 1, we can see with details, type lecturer classified into several sections, this is related to figure 6 , and in table 1 the classification becomes more clear and details. This classification can be explained as follows:

Type D1 (Dream) is a lecturer type who has a high dream and is a lecturer who has a dream vision type, where the dream is too high so it may be difficult to achieve, this is the negative side, on the positive side, this lecturer is a lecturer who has ambition which is high, so always excited in its cultivation. If the lecturer is classified into more details, it will produce $\mathrm{D} 1+\mathrm{D} 1$, which is a dream lecturer, but never reaches that dream, because it is so high that it is difficult to achieve; D1 + D2, is a lecturer type who has dreams but at the same time dare to act for the dream, but this type of lecturer requires direction and/or supervise so that his dream can be achieved; D1 + D3, is a lecturer who acts consistently to achieve his dream, this lecturer is the most sought after lecturer because it has a toughness in consistency in developing himself; D1 + B, is a lecturer who has high confidence and dreams to achieve, but this type of lecturer also still requires directed so that his confidence does not result to pride.

Type D2 (Dare) is a brave lecturer who accepts new challenges in developing him, this is a positive side of the lecturer of this type, the negative side of this type is the lack of empathy in social interaction. This type, if classified, can be explained as follows: D2 + D1, is a type of lecturer who has high courage and has high dreams, lecturers of this type, have great ambitions in reaching what he has planned, for example, will follow the international certificate - but does not stop just as a participant, the lecturer will actually get the certificate; D2 + D2, this type of lecturer has very high courage, but does not have good planning, so that what is planned is not achieved and/or not fully achieved; D2 + D3, this type of lecturer is equal to D2 $+\mathrm{D} 1 ; \mathrm{D} 2+\mathrm{B}$, this type of lecturer is a lecturer who has the courage and believes that the whole plan will be fully achieved, with excellent planning-details and very consistent.

Type D3 (Do) is a brave lecturer in doing something and while doing so the lecturer is really doing wholeheartedly, the negative side of this lecturer is to be guided to stay on the path specified by the University. Such a type can be classified as follows: D3 + D1, a lecturer who believes that his inner achievements can be achieved with the power of dreams, this type should always be motivated to actually move and do what has been planned; D3 + D2, lecturers of this type dare to act with what has been planned and try hard to achieve it; D3 + D3, this type of lecturer is a lecturer who is totally acting but without careful calculation, so that almost all plans are not achieved and/or only partially achieved; D3 + B, same as type D3 + D2; D3 + B, this type of lecturer is a lecturer who acts if there is a clear command from the boss at the University, and lecturers of this type will not want to do it until the order is clear.

Type B (Believe), this type of lecturer is a lecturer with very good confidence level, sincerely believes that any achievement will be given entirely to students and universities, lecturers of this type will be very attentive to others and have high empathy; the negative side of this type of lecturer is if not, this lecturer will really not want to do it. The classification is as follows: B + D1, lecturers of this type lecturers who have high confidence and high dreams, this lecturer will achieve anything because of the regularity and consistency it has; B + D2, this type of lecturer is a lecturer who has high confidence and dare to act with what he has said and/or full commitment to the university; B + D3, this type of lecturer is a lecturer who has high confidence and immediately does what he has said; B + B, this type of lecturer is a lecturer who only believes, but does nothing to achieve what he has planned.

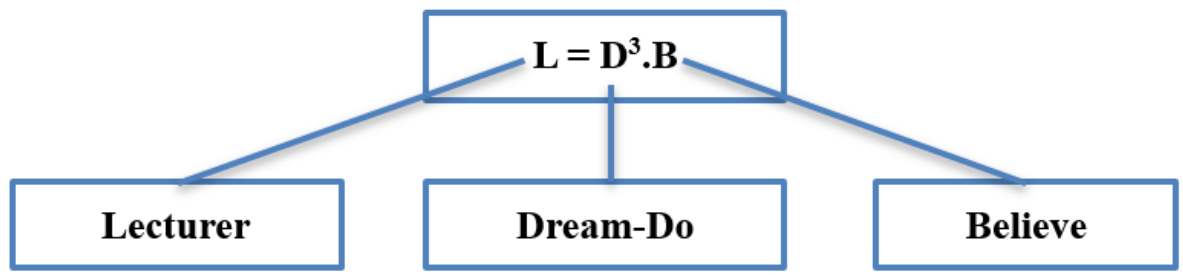

Figure 10. The Formula- $\mathrm{L}=\mathrm{D}^{3} \cdot \mathrm{B}$ 
According to figure 10, we create a formula to develop lecturers' resources within the university, which is very important to do immediately, because we are facing globalization and rapid change. A theory says: Glocalization theory fuses relationships, balance, and harmony between cultural homogenization and heterogenization, standardization and adaptation, homogenization and tailoring, convergence and divergence, and universalism and particularism (Matusitz, 2011). The new millennium has seen rapid change in many aspects and segments of manufacturing industries. Some factors contributing towards this change are: (1) Intense global competition; (2) Mass markets fragmenting into niche markets; (3) Customers expecting low volume, high quality, custom products; (4) Seemingly ever-shortening product life-cycles, development times, and production lead times are required; (5) Customers want to be uniquely treated, i.e. as individuals(Khalil \& Weston, 2010). From this theory, we can see that adaptation is an important word in change, adaptation must be applied comprehensively, resulting in cultural changes that can help in transforming human resources and producing beneficial changes. Therefore, An enterprise needs to select the tools for the performance assessment. The system for performance management can automatically be upgraded. Based on the identities of inspected targets, the system will select the competitive tools for the performance evaluation (Wang, Wang, $\mathrm{Bi}, \mathrm{Li}, \& \mathrm{Xu}, 2016$ ). The next is common to the different perspectives that the heterogeneity can have both negative and positive consequences for groups (Martín-Alcázar, Romero-Fernández, \& Sánchez-Gardey, 2012), and this is a thing that should be kept to balance, and here needed a very good management, Strong management capacity at all levels of the health system, including frontline supervision, is vital to improving work performance in areas of recovering from conflict (Roome, Raven, \& Martineau, 2014). Strong leadership and management skills are crucial to finding solutions to the human resources crisis in health. Health professionals and human resources (HR) managers worldwide who are in charge of addressing (Sherk, Nauseda, Johnson, \& Liston, 2009). According to Arthur (1992, 1994), HR systems can be classified as " control " or " commitment " systems. Control HR systems rely on enforcing employee compliance with specified rules and efficiency improvement and direct labor cost reduction (Uen, Chien, \& Yen, 2009). In this case, it takes human resources to control, so the system can be run effectively and efficiently, According to Noe et al. (1994), major privacy concerns include determinations about (1) what kind of employee information should be stored on the system (eg, salary and medical information), (2) who has access to computer hardware and data, and (3) who can access and modify databases (Hubbard, Forcht, \& Thomas, 1998).

Formula $\mathrm{L}=\mathrm{D}^{3}$. B, has the following advantages: (1) The University will be able to obtain a lecturer who has high quality, has experience in his field and knowledge in accordance with what is required by the University; (2) Students will have lecturers who are not only knowledgeable and taught by lecturers who have experience in their field; (3) Industrial world can have human resources according to requirement, because university can produce human resource having competency required by company / organization; (4) The occurrence of synchronization between industry and university, so there is a balance between the two; (5) Significant cultural change will occur, when knowledge and experience are equilibrium; (6) The University will produce innovative products / services so that the needs of society will be met very well; (7) The occurrence of changes in daily lifestyle patterns; mindset; behavior in the face of globalization, and can be in line with advances in information technology(Gamayanto, n.d.), which can be called human technology significantly, not just theoretical. The next most important question is: How the implementation of the formula into the university level, so that it can meet the seven things mentioned above:

First, the filter must be done by the university at the time of admission of the lecturer. We know that acceptance is now based on academic potential tests, psychological tests and some other tests to meet existing formal societies, but the question is: will the test guarantee that we will get a high quality lecturer ?, we feel that this is still maximum, there is an undetected missing link, for example: mindset, character and also related to the psychology of the lecturer, if this is not handled properly, then problems arise such as sexual harassment, violence and negative things that the university would not want to do to prevent this, the university could apply the formula. The stages are: (1) Test of academic potential and psychological test may be performed only to fulfill formal society, but the result cannot guarantee to know the whole, in this case can still be done; (2) The second point is the most important point, the interview conducted by the dean should be able to focus on the formula, the first question to ask is: (a) What is your goal to become a lecturer? - this is to be able to know the real dream, so lecturers can lie while doing so, but body language cannot deceive it, so this question needs to be asked. From this question will be known the purpose of being a lecturer; (b) What is the next action after you have that dream? - this question is to know the dare and do that lecturer has, how to achieve it and why the lecturer has the dream; (c) the last question to ask is: are you confident about achieving that?, this question is to be able to assess the level of commitment that has been answered in the first and second points. If these three questions cannot be answered and / or hesitated to answer, then the university does not accept the lecturer, this also refers to what has been said by Warren Buffett: "In looking for people to hire, you have to look for people with 3 qualities: integrity, intelligence and energy, and if you do not 
have the first, the other two will kill you. Think about it, this is true. If you employ people without integrity, you really want them to be stupid and lazy".

Second, when the lecturer is acceptable and able to answer to the three questions asked, then the next process is to apply the formula $\mathrm{L}=\mathrm{D}^{3}$. B, to achieve the result that is $\mathrm{L}$. Lecturer every semester must have a target to be achieved, and really must be attainable, not just in a "talking but not producing" position or "Just saying promises to achieve that, but never reaching". The target should be measured and supervised by the dean and/or department head, here the leader should direct the lecturer that the achievement must be realistic and not just show off, the result should be able to contribute both concept and/or implementation to the community. During this time, we see what is produced only in the form of theoretical contributions and very powerful concepts with complex formulas to understand, this is not wrong, but the important thing is whether the concept can have an impact on the change of mindset and attitude of the community so that it can form better culture resulting in innovations in different sectors of life. For example, a concept is the result of deep-seated thinking in the long run and is a result of indepth observation and experience gained, the concept must be able to give vibration changes in feelings and trigger deeper thinking to be willing to change his attitude towards a certain condition and/or situation, thus forming a growing personality in a positive manner.

Third, to produce something and earn producer, are two different things that must be understood correctly. A lecturer must be able to generate a contribution to the university and the community, to produce the means of contributing the greatest within his entire mindset to produce an applied innovation, in which society will be able to live a better life and/or a company can apply it to produce profits in the right way and integrity. Earnings are special bonuses earned on generating things. First of all, our mindset must be changed by not only focusing on how much income it earns when creating it, the producer will come at a time when our motivation is right, that is to contribute to the progress of man and the world. This is the psychological and life side that should be fully understood so that the lecturer can work by giving all his capabilities. This awareness must be instilled by leaders at the university so that change will be a real change, not just a change that is only in the outer layer.

Fourth, by the time the three points above have been done, the cooperation with private and government companies should be improved, where the final task and/or practical work is done in completing the study at the university, should be able to create something that can generate a concept that can provide input a new system and processes that can be applied to produce perfect output. Perfection means a process that starts with the correct input so that the resulting output positively impacts change.

\section{Conclusions}

- Disneyland Concepts- Dream; Dare; Do; Believe, is a concept that can be applied flexibly to various organizations so that organizations can develop human resources significantly and generate huge profits

- Formula $\mathrm{L}=\mathrm{D}^{3} . \mathrm{B}$, applicable within the university, to find high-quality lecturer resources and generate student resources to truly benefit the State

- Applying the formula $\mathrm{L}=\mathrm{D}^{3}$. $\mathrm{B}$ requires a very strong commitment and requires solid cooperation, especially with top management within the university to be able to really run the formula

- This research is very useful for universities, because the university will be able to find out the right position for the lecturers so that the university environment will be able to create an innovative and creative environment, furthermore, the formula $\mathrm{L}=\mathrm{D}^{3}$. $\mathrm{B}$ will be able to improve the lecturer's ability from two sides, knowledge and experience

\section{Recommendations}

- The most important and the first thing the University should do is to put people in the right position and only those with the competencies that should be maintained, if this is done then the process of the formula $\mathrm{L}=\mathrm{D}^{3}$. $\mathrm{B}$, can only be executed effectively and efficiently

- The university only accepts lecturers who really have balance-based capabilities, which means knowledge based on their current competencies, high commitment to developing and knowledge based on an experience of their capability, with which students will be able to gain the maximum benefit in the learning process

\section{Acknowledgments}

We are grateful to Hanny Haryanto (artificial intelligence Game specialist) who has given an in-inspiration on how university human resources should be positively developed; Mr.Henry Christian, as a business owner, providing information and assisting in collecting the required data, a businessman with the necessary research and expertise 
in applicable practical logic and information on what industry / company / organization needs; Abas (Virutal reality-game development), which contributes greatly to local culture and develops it in a virtual-benthix game, a study we are developing till now; Rizka Nugraha (management specialist, leadership and human resources) - who has helped a lot in the survey. Some people who help in surveys and interviews, so this journal can be completed perfectly.

\section{References}

Gamayanto, I. (n.d.). PORTER'S FIVE FORCES MODEL; SCOTT MORTON'S FIVE FORCES MODEL; BAKOS AND .... (Indra Gamayanto) PORTER'S FIVE FORCES MODEL; SCOTT MORTON'S FIVE FORCES MODEL; BAKOS \& TREACY MODEL ANALYZES [STRATEGIC INFORMATION SYSTEMS MANAGEMENT]. Retrieved from http://puslit.petra.ac.id/journals/informatics/

Hubbard, J. C., Forcht, K. A., \& Thomas, D. S. (1998). Human Resource Information Systems: An Overview of Current Ethical and Legal Issues, 1319-1323.

Khalil, S. N., \& Weston, R. H. (2010). Modelling Human Resource Systems in Support of Efficient Production, 72-79. https://doi.org/10.1007/978-3-642-14341-0_9

Martín-Alcázar, F., Romero-Fernández, P. M., \& Sánchez-Gardey, G. (2012). Transforming Human Resource Management Systems to Cope with Diversity. Journal of Business Ethics, 107(4), 511-531. https://doi.org/10.1007/s10551-011-1061-0

Matusitz, J. (2011). Disney's successful adaptation in Hong Kong: A glocalization perspective. Asia Pacific Journal of Management, 28(4), 667-681. https://doi.org/10.1007/s10490-009-9179-7

Pratikna, R. N., \& Gamayanto, I. (2017). Developing Leadership Systems Inside University Using Jim Collins Method [ Good to Great ]: People Management Development to Face ASEAN Economic Community in Indonesia. Review of Integrative Business and Economics Research, 6(3), 45-55.

Roome, E., Raven, J., \& Martineau, T. (2014). Human resource management in post-conflict health systems: the review of research and knowledge gaps. Conflict and Health, 8, 18. eCollection 2014. https://doi.org/10.1186/1752-1505-8-18

Sherk, K. E., Nauseda, F., Johnson, S., \& Liston, D. (2009). An experience of virtual leadership development for human resource managers. Human Resources for Health, 7, 1-3. https://doi.org/10.1186/1478-4491-7-1

Uen, J., Chien, M. S., \& Yen, Y. F. (2009). The Mediating Effects of Psychological Contracts on the Relationship Between Human Resource Systems and Role Behaviors: A Multilevel Analysis. Journal of Business and Psychology, 24(2), 215-223. https://doi.org/10.1007/s10869-009-9101-9

UNESCO, Indonesia, (2018), UNESCO Indonesia-Education Systems, UNESCO Institute of Statistics.

Wang, X. L., Wang, L., Bi, Z., Li, Y. Y., \& Xu, Y. (2016). Cloud computing in human resource management (HRM) system for small and medium enterprises (SMEs). International Journal of Advanced Manufacturing Technology, 84(1-4), 485-496. https://doi.org/10.1007/s00170-016-8493-8

\section{Copyrights}

Copyright for this article is retained by the author(s), with first publication rights granted to the journal.

This is an open-access article distributed under the terms and conditions of the Creative Commons Attribution license (http://creativecommons.org/licenses/by/4.0/). 